\title{
Influence of Microstructural Changes on Some Macro Physical Properties of Cement Mortar during Accelerated Carbonation
}

\author{
Son Tung Pham \\ National Institute of Applied Sciences, Rennes, France \\ Email: phamsontung82@yahoo.com
}

Received 29 March 2014; revised 29 April 2014; accepted 6 May 2014

Copyright (C) 2014 by author and Scientific Research Publishing Inc.

This work is licensed under the Creative Commons Attribution International License (CC BY). http://creativecommons.org/licenses/by/4.0/

(c) (i) Open Access

\begin{abstract}
The objective of this work was to examine the changes in the microstructure and macro physical properties caused by the carbonation of normalised CEM II mortar. Samples were prepared and subjected to accelerated carbonation at $20^{\circ} \mathrm{C}, 65 \%$ relative humidity and $20 \% \mathrm{CO}_{2}$ concentration. On the microstructure scale, the evolutions of the cumulative pore volume, pore size distribution, and specific surface area during carbonation were calculated from the adsorption desorption isotherms of nitrogen. We also examined the evolution of macro physical properties such as the solid phase volume using helium pycnometry, porosity accessible to water, gas permeability, and thermal conductivity. The conflict between nitrogen porosity and water porosity results indicated that the porous domains explored using these two techniques are different and help to complementarily evaluate the effects of carbonation. This is a multi-scale study where results on microstructural changes can help to explain the evolution of macro physical properties.
\end{abstract}

\section{Keywords}

Carbonation, Cement Mortar, Microstructure, Nitrogen Adsorption, Gas Permeability, Thermal Conductivity

\section{Introduction}

Under the action of carbon dioxide from the air and with the presence of water in the pores, several constituents of the cement material are carbonated and form calcium carbonate. The principle reactions are:

The carbonation of portlandite:

$$
\mathrm{CO}_{2}+\mathrm{Ca}(\mathrm{OH})_{2}=\mathrm{CaCO}_{3}+\mathrm{H}_{2} \mathrm{O}
$$

How to cite this paper: Pham, S.T. (2014) Influence of Microstructural Changes on Some Macro Physical Properties of Cement Mortar during Accelerated Carbonation. Open Journal of Civil Engineering, 4, 85-91. 
The carbonation of calcium silicate hydrate C-S-H:

$$
\mathrm{C}_{\mathrm{a}} \mathrm{S}_{\mathrm{b}} \mathrm{H}_{\mathrm{c}}+\mathrm{aH}_{2} \mathrm{CO}_{3}=\mathrm{aCaCO}_{3}+\mathrm{bSiO}_{2} \cdot \mathrm{dH}_{2} \mathrm{O}+(\mathrm{a}-\mathrm{d}+\mathrm{c}) \mathrm{H}_{2} \mathrm{O}
$$

The progress of these carbonation reactions causes a change in the microstructure, which is highlighted by various parameters such as variations in porosity, specific surface area and pore size distribution. These microstructural evolutions during carbonation lead obviously to changes in macro physical properties such as the solid phase volume, the gas permeability, and the thermal conductivity.

The coherence between the observations on micro and macro scales is still discussed. While most authors have observed a decrease in the porosity accessible to water [1] [2], this result can not explain the increase in the gas permeability observed by some authors [1] [3]. Some investigators believe that the water molecule, because of its small radius of $0.1 \mathrm{~nm}$ [4], can penetrate not only into meso and macro pores (radius larger than $2 \mathrm{~nm}$ ) but also into nano- and micropores [5]. Hence, the water porosity decreases after carbonation means that the totality of pores decreases, but no specific information about the meso and macro pores, the porous domains which influence the gas permeability, can be drawn.

Although the mercury porosimetry method is suitable for meso and macro pores with radii of $2 \mathrm{~nm}$ to $60 \mu \mathrm{m}$, the high pressure which is needed to intrude the mercury into the pores might lead to the micro damage during the test and influence the results [6]. For this reason, we propose to investigate the evolution of the microstructure caused by the carbonation in a cementitious matrix using nitrogen adsorption, which is suitable for meso pores with radii of $2 \mathrm{~nm}$ to $32 \mathrm{~nm}$. We will report the change in the following areas: the cumulative pore volume, the BET specific surface area [7], and the pore size distribution. The observations on microstructural changes will help to discuss the evolutions of macro properties that we propose to measure, such as the solid phase volume, the gas permeability, and the thermal conductivity. Although the thermal conductivity is important for fire resistance and energy conservation, its evolution during carbonation of cement materials has never been studied.

\section{Materials and Methods}

\subsection{Standardised Mortar CEM II}

For this study, we used a normalised mortar prepared with Lafarge cement CEM II/BM (V-LL) $32.5 \mathrm{R}$ and French standard sand certified in accordance with norm EN 196-1 and ISO 679:2009. The water/cement and sand/cement ratios were 0.5 and 3, respectively. At the end of the mixing, the mortar was placed in cylindrical moulds $(\varnothing=40 \mathrm{~mm}, \mathrm{~h}=60 \mathrm{~mm}$ ). The samples were demoulded after 24 hours and then cured for 90 days in a humid chamber $\left(20^{\circ} \mathrm{C}, 100 \%\right.$ relative humidity).

\subsection{Carbonation Test}

Before the carbonation test, the samples were dried at $105^{\circ} \mathrm{C}$ to a constant mass and then stored for 7 days at $20^{\circ} \mathrm{C}, 65 \%$ relative humidity for homogenisation in the internal humidity. To implement the test, the samples were protected laterally using an adhesive tape and then subjected to axial diffusion of $\mathrm{CO}_{2}$ in an environmentally controlled chamber at $20^{\circ} \mathrm{C}, 65 \%$ relative humidity and $20 \% \mathrm{CO}_{2}$ concentration for a defined time. At the end of the test, the carbonated zone was determined using the classical phenolphthalein test.

\subsection{Nitrogen Adsorption Desorption}

The nano- and microscopic scales consist of sheets of C-S-H. These sheets associated with packets are called grains and constitute a second level of the observation, which is the mesoscopic scale. To study this scale, we record the nitrogen adsorption-desorption isotherms. The test is performed on grinding powders originating from the test samples. Nitrogen molecules are indeed adsorbed to the surface of grains corresponding to the packets of the sheets of C-S-H and to the packets of portlandite; however, they do not penetrate the space between the layers. The specific surface area analyser Micromeritics Gemini VII was used for this test. From adsorption desorption isotherms of nitrogen, the BET specific surface area [7] and the BJH pore size distribution [8] were calculated.

\subsection{Gas Permeability}

The test was performed in a helium permeameter under variable pressures: 1 bar, 2 bars, 3 bars, and 5 bars. For each pressure, we waited for the gas flow to become constant. The intrinsic permeability $\mathrm{K}$ was then calculated 
in accordance with CEMBUREAU method [9].

\subsection{Thermal Conductivity}

The thermal conductivity was performed at $20^{\circ} \mathrm{C}$ using a Hot Disk Thermal Constants analyser. A plane Hot Disk sensor was fitted between two pieces of the sample - each one with a plane surface facing the sensor. By passing an electrical current, high enough to increase the temperature of the sensor between a fraction of a degree up to several degrees, and at the same time recording the resistance (temperature) increase as a function of time, the Hot Disk sensor was used both as a heat source and as a dynamic temperature sensor.

\subsection{Determination of the Actual Volume}

The actual volume was determined using helium pycnometry. This method consists of injecting a gas at a given pressure in a container of known internal volume containing the sample and then relaxing it in a second chamber of known volume. The measure of the new equilibrium pressure is used to calculate the actual volume of the sample using the ideal gas law. Micromeritics helium pycnometry AccuPyc II 1340 was used for this measurement.

\section{Results and Discussion}

\subsection{Nitrogen Adsorption Desorption Isotherms}

In Figure 1, we present the nitrogen adsorption isotherms for the two types of samples (carbonated and noncarbonated). When comparing the isotherms of the carbonated sample with those of the non-carbonated sample, we observe that nitrogen adsorption on the carbonated sample is more significant.

Regarding the pore distribution curves (Figure 2), we observe that the carbonation results in a decrease in the micropore volume and an increase in the mesopore volume. The carbonation of portlandite is manifested by the crystallisation of numerous calcite crystals on the portlandite platelets. It is therefore understandable that the carbonation results in an increase in the specific surface area (Table 1) and a modification of the pore network.

\subsection{Total Porosity}

The porosity accessible to water was determined by the classical method using hydrostatic weighing [10]. The results, which are summarised in Table 2, reveal a clear decrease in porosity. Similar results have already been reported in the literature [1] [2]. This result is therefore opposite in comparison with the result obtained by the nitrogen adsorption (Figure 3). Both techniques seem to imprecisely cover the same porous domains. According to Belie et al. [5], the size of nitrogen molecules does not allow them to access the microporosity of the C-S-H, whereas the water molecules can enter these micropores. It is therefore likely that the domain involved in the nitrogen adsorption test is essentially the mesoporous domain.

In the domain of nano and micro pores, the calcium carbonate formed during carbonation obstructs the pores, by consequence, the water accessible porosity decreases. This decrease in the volume of micropores was confirmed in Figure 2 where we presented the pore size distribution calculated from nitrogen adsorption desorption.

\subsection{Carbonation Depth}

In Figure 4, we observe that the carbonation propagation is a linear function with the square root of the duration of carbonation. This result is coherent with the prediction of carbonation depth in literature: $x=A \cdot \sqrt{t}[11]$, where $\mathrm{A}$ is a constant taking into account both the composition of the cement material (water/cement ratio, type of binder, ...) and the environmental conditions (relative humidity, temperature, pressure, ...).

\subsection{Porosity Accessible to Water-Gas Permeability-Thermal Conductivity}

The results in Figure $\mathbf{5}$ show that the more the sample is carbonated, the more the porosity accessible to water decreases. When the $\mathrm{CO}_{2}$ reach deeper in the cement matrix (Figure 4), the quantity of products of carbonation $\left(\mathrm{CaCO}_{3}\right)$ becomes bigger and therefore the porosity decreases. In combination with the results determined by ni- 


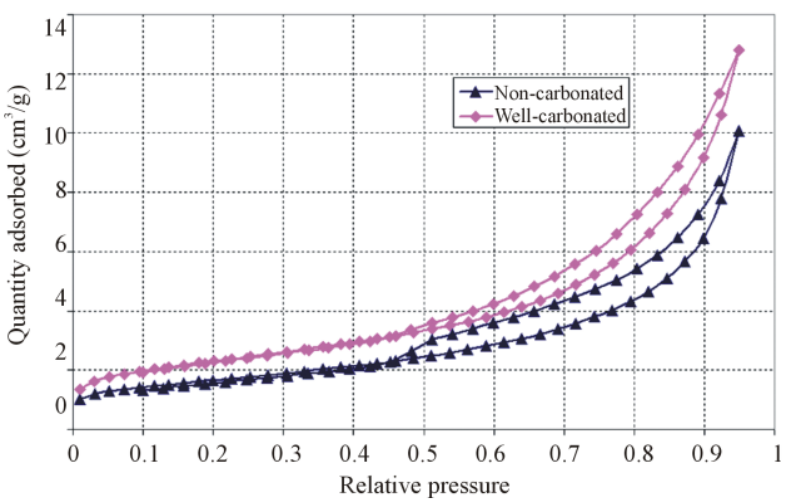

Figure 1. Nitrogen adsorption desorption on the powder sample.

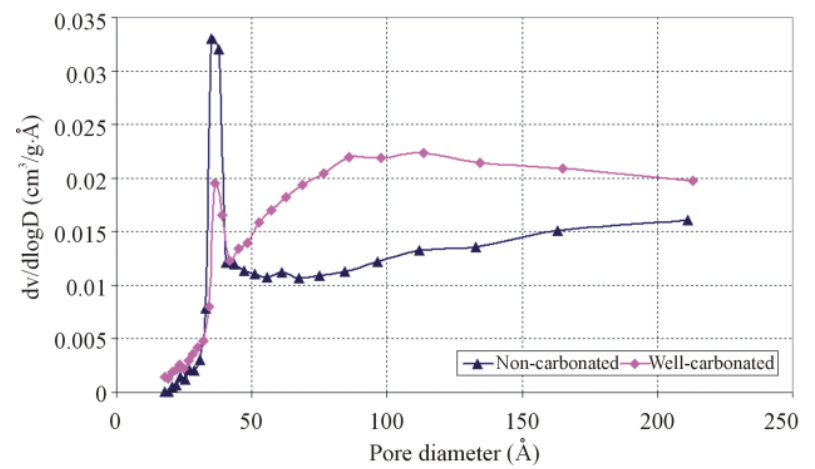

Figure 2. Pore size distribution determined from nitrogen desorption branch of the powder sample.

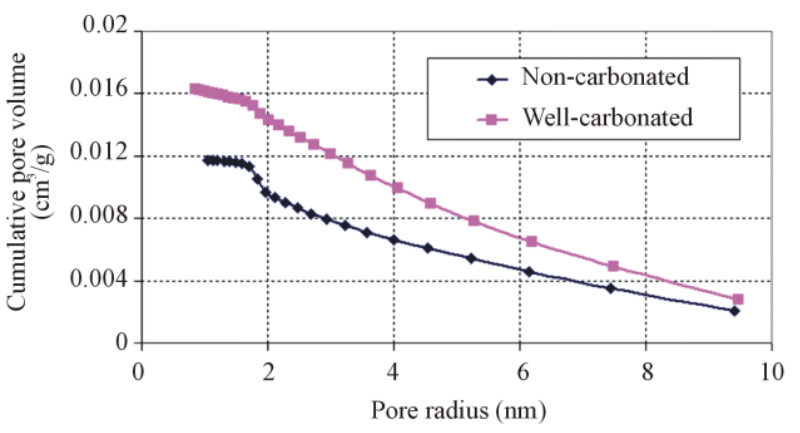

Figure 3. Cumulative pore volume determined by nitrogen adsorption.

Table 1. Specific surface area of non-carbonated and well-carbonated mortars.

\begin{tabular}{cc}
\hline & $\mathrm{BET}_{\text {nitrogen }}\left(\mathrm{m}^{2} / \mathrm{g}\right)$ \\
\hline Non-carbonated & $5.1 \pm 0.8$ \\
Well-carbonated & $7.7 \pm 0.7$ \\
\hline
\end{tabular}

Table 2. Water-accessible porosity of non-carbonated and well-carbonated mortars.

\section{Porosity (\%)}

Non-carbonated

$19 \pm 0.2$

Well-carbonated

$16.1 \pm 0.2$ 


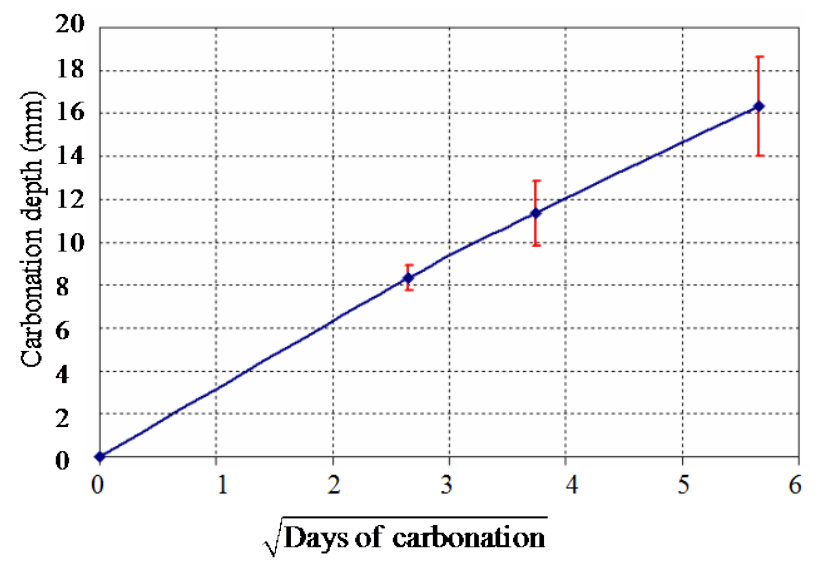

Figure 4. Evolution of the carbonation depth in function of time.

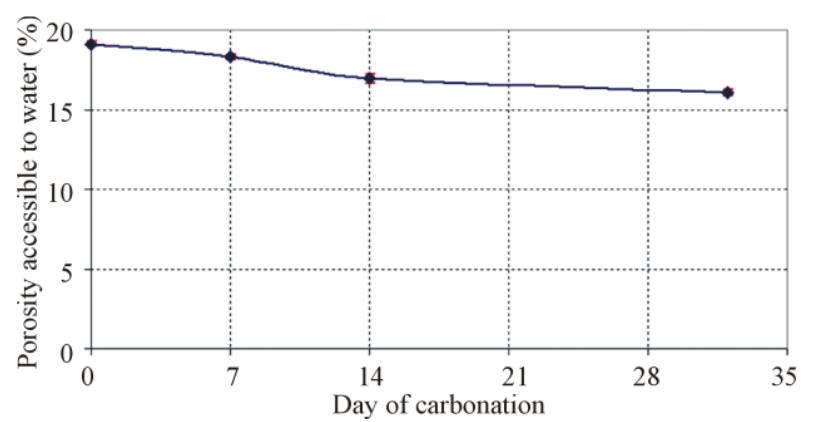

Figure 5. Evolution of the porosity accessible to water during carbonation.

trogen adsorption, it seems that the decrease in the total porosity is mostly because of the decrease in the volume of micro pores. In contrast, the volume of mesopores increases with the carbonation. We also observed an increase in the intrinsic permeability to helium as presented in Figure 6. The results showed that the evolution of the gas permeability during carbonation is largely influenced by the changes in mesoporous domain.

Figure 7 presents the thermal conductivity during carbonation. We observe an increase in the thermal conductivity as a function of the carbonation duration. Due to the low thermal conductivity of the air, the thermal conductivity varies with the density [12]. Hence, the increase in the thermal conductivity during carbonation is coherent with the decrease of the total porosity.

\subsection{Solid Phase Volume Determined by Helium Pycnometry}

The actual volumes of the solid phases were determined using helium pycnometry on two groups of samples before and after the period of carbonation. The results are presented in Figure 8. We can see clearly that the accelerated carbonation resulted in a significant increase in the actual volume in comparison with the reference sample, which was maintained at $20^{\circ} \mathrm{C}$ and $65 \%$ relative humidity without additional $\mathrm{CO}_{2}$. The increase in the volume of the solid phase can be explained by the formation of $\mathrm{CaCO}_{3}$ during carbonation. Because the carbonation of one mole of portlandite leads to an increase in volume of $4 \mathrm{~cm}^{3}$ [13] [14], and the carbonation of one mole of C-S-H leads to an increase in volume of $12 \mathrm{~cm}^{3}[15]$ or $39 \mathrm{~cm}^{3} / \mathrm{mol}$ [4], the $\mathrm{CaCO}_{3}$ clogs the pores, thereby decreasing the porosity.

\section{Conclusions}

The results of this study indicate that nitrogen and water molecules do not get access into the same porous domains. Investigation using nitrogen adsorption gives information mainly about meso pores, while the one using 


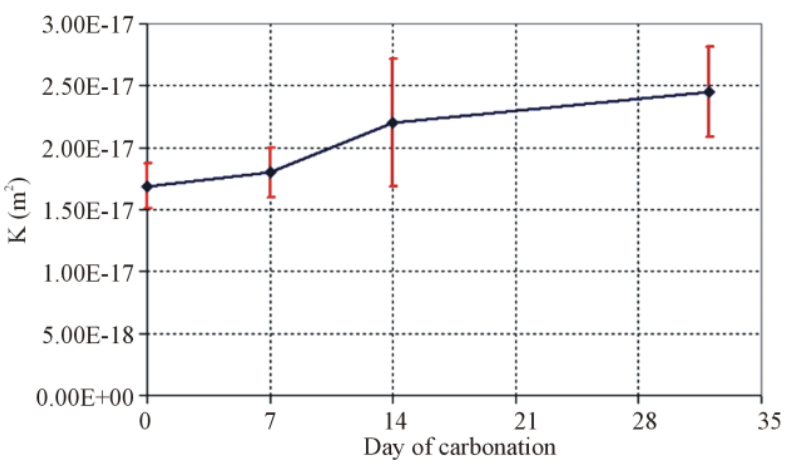

Figure 6. Evolution of the intrinsic permeability to helium during carbonation.

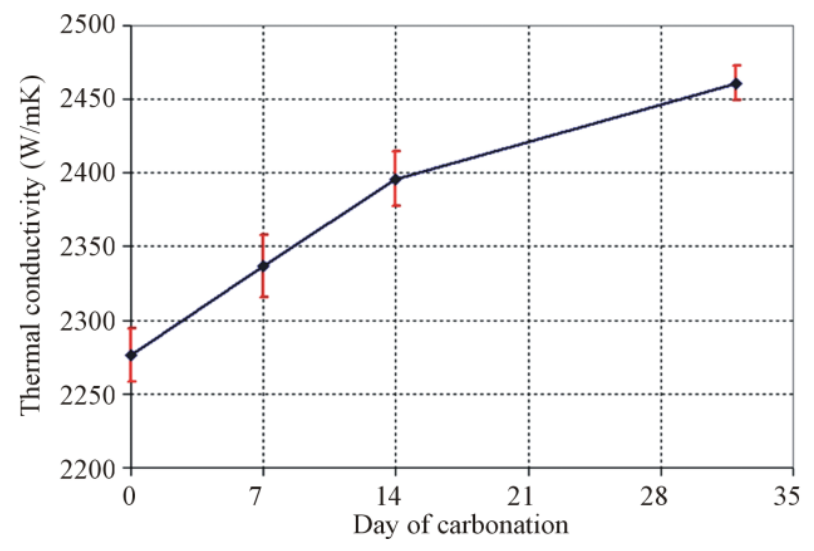

Figure 7. Evolution of the thermal conductivity during carbonation.

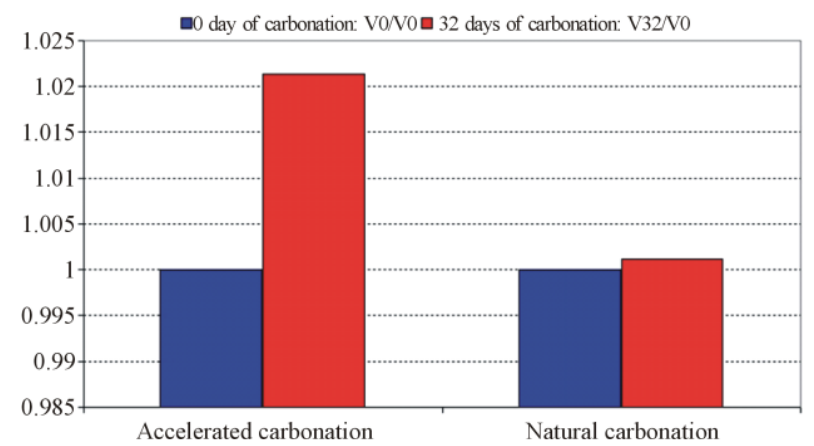

Figure 8. Ratio of the actual volume measured after 32 days of carbonation and the actual volume measured on day 0 of carbonation.

water-accessible porosity covers all three domains: macro, meso and micropores.

Thus, the porosity and specific surface area determined by nitrogen adsorption increase when carbonation occurs. After carbonation, the amount of nitrogen adsorbed at a given relative pressure increases substantially, and the adsorption occurs mainly for pore sizes larger than $2 \mathrm{~nm}$ (the mesoporous domain).

In contrast, the porosity accessible to water decreases after carbonation. The combination of the two techniques allows drawing a conclusion that, after carbonation, the volume of meso pores increases at the expense of the volume of micropores.

The decrease in the volume of micro pores is explained by the formation of $\mathrm{CaCO}_{3}$ during carbonation that 
obstructs the pores. These results in the increase of the solid phase volume are determined by helium pycnometry. Another consequence is the increase of thermal conductivity after carbonation.

It appears that the gas intrinsic permeability is mostly influenced by the meso pores. The results show that the increase in volume of meso pores after carbonation might be the cause of the increase in the intrinsic permeability to helium.

\section{References}

[1] Mickaël, T. (2005) Modelling of Atmospheric Carbonation of Cement Based Materials Considering the Kinetic Effects and Modifications of the Microstructure. Ph.D. Thesis, L'école Nationale des ponts et Chausses, Paris.

[2] Ngala, V.T. and Page, C.L. (1997) Effects of Carbonation on Pore Structure and Diffusional Propeties of Hydrated Cement Pastes. Cement and Concrete Research, 27, 995-1007. http://dx.doi.org/10.1016/S0008-8846(97)00102-6

[3] Jaafar, W. (2003) Influence de la Carbonatation sur la Porosité et la Perméabilité des Bétons. Diplôme d'Etudes Approfondies (Master of Advanced Studies), Laboratoire Central des Ponts et Chaussées, Paris.

[4] Hiromitu, N. and Masako, H. (1991) Analysis of Adsorption Isotherms of Water Vapour for Nonporous and Porous Adsorbents. Journal of Colloid and Interface Science, 145, 405-412. http://dx.doi.org/10.1016/0021-9797(91)90371-E

[5] De Belie, N., Kratky, J. and Van Vlierberghe, S. (2010) Influence of Pozzolans and Slag on the Microstructure of Partially Carbonated Cement Paste by Means of Water Vapour and Nitrogen Sorption Experiments and BET Calculations. Cement and Concrete Research, 40, 1723-1733. http://dx.doi.org/10.1016/j.cemconres.2010.08.014

[6] Zhang, Q., Ye, G. and Koenders, E. (2013) Investigation of the Structure of Heated Portland Cement Paste by Using Various Techniques. Construction and Building Materials, 38, 1040-1050. http://dx.doi.org/10.1016/j.conbuildmat.2012.09.071

[7] Brunauer, S., Emmett, P.H. and Teller, E. (1938) Adsorption of Gases in Multimolecular Layers. Journal of American Chemical Society, 60, 309. http://dx.doi.org/10.1021/ja01269a023

[8] Barrett, E.P., Joyner, L.G. and Halenda, P.P. (1951) The Determination of Pore Volume and Area Distributions in Porous Substances. I. Computations from Nitrogen Isotherms. Journal of the American Chemical Society, 73, 373-380. http://dx.doi.org/10.1021/ja01145a126

[9] Kollek, J.J. (1989) The Determination of the Permeability of Concrete to Oxygen by the CEMBUREAU Method-A Recommendation. Materials and Structures, 22, 225-230. http://dx.doi.org/10.1007/BF02472192

[10] Association Française pour la Construction et pour la Recherche et les Essais sur les Matériaux et les Constructions, (1997) Détermination de la Masse Volumique Apparente et de la Porosité Accessible à l'eau. In: Ollivier, J.P., Ed., Durabilité des béton-Méthodes Recommandées pour la Mesure des Grandeurs Associées à la Durabilité, Laboratoires des Matériaux et Durabilité des Constructions, Toulouse, 121-124.

[11] Association Française de Génie Civil (2004) Conception des Bétons pour une Durée de vie Donnée des Ouvrages. Paris.

[12] Neville, A.M. (1990) Properties of Concrete. Longman Scientific and Technical, London.

[13] Houst, F.Y. and Wittmann, F.H. (1989) Retrait de Carbonatation. IABSE Symposium, Lisbon, 255-260.

[14] Papadakis, V.G., Vayenas, C.G. and Fardis, M.N. (1989) A Reaction Engineering Approach to the Problem of Concrete Carbonation. AIChE Journal, 35, 1639-1650. http://dx.doi.org/10.1002/aic.690351008

[15] Papadakis, V.G., Vayenas, C.G. and Fardis, M.N. (1991) Fundamental Modelling and Experimental Investigation of Concrete Carbonatation. ACI Material Journal, 88, 363-373. 